\title{
Idiopathic Central Precocious Puberty
}

National Cancer Institute

\section{Source}

National Cancer Institute. Idiopathic Central Precocious Puberty. NCI Thesaurus. Code C120372.

Central precocious puberty for which no underlying cause can be identified. 